\title{
Visceral leishmaniasis caused by Leishmania infantum in a Spanish patient in Argentina: What is the origin of the infection? Case
} report

\author{
Joaquina Martín-Sánchez*1, José M Navarro-Mari², Juan Pasquau-Liaño3, \\ Oscar D Salomón ${ }^{4}$ and Francisco Morillas-Márquez ${ }^{1}$
}

\begin{abstract}
Address: ${ }^{1}$ Departamento de Parasitología, Facultad de Farmacia, Campus Universitario de Cartuja 18.071, Universidad de Granada, Spain 2Servicio de Microbiología, Hospital Universitario "Virgen de las Nieves", Granada, Spain, ${ }^{3}$ Unidad de Enfermedades Infecciosas, Hospital Universitario "Virgen de las Nieves", Granada, Spain and ${ }^{4}$ Centro Nacional de Diagnóstico e Investigación en endemo-Epidemias (CeNDIE), Administración Nacional de Laboratorios e Institutos de Salud Dr. Carlos G. Malbrán (ANLIS), Ministerio de Salud, Argentina

Email: Joaquina Martín-Sánchez* - joaquina@ugr.es; José M Navarro-Mari - josem.navarro.sspa@juntadeandalucia.es; Juan PasquauLiaño - pascuau@juntadeandalucia.es; Oscar D Salomón - danielsalomon@hotmail.com; Francisco Morillas-Márquez - fmorilla@ugr.es

* Corresponding author
\end{abstract}

Published: 29 June 2004

BMC Infectious Diseases 2004, 4:20 doi:10.1 186/147/-2334-4-20

This article is available from: http://www.biomedcentral.com/I47I-2334/4/20

(C) 2004 Martín-Sánchez et al; licensee BioMed Central Ltd. This is an Open Access article: verbatim copying and redistribution of this article are permitted in all media for any purpose, provided this notice is preserved along with the article's original URL.
Received: 24 February 2004

Accepted: 29 June 2004

\begin{abstract}
Background: The question "Where have you been?" is a common one asked by doctors in Northern Europe and America when faced with clinical symptoms not typical of their country. This question must also arise in the clinics of developing countries in which non-autochthonous cases such as the one described here can appear. Important outbreaks of Leishmania infantum have been recorded in the last decade in several Latin American countries but its presence has not yet been recorded in Argentina. We report the first case of visceral leishmaniasis owing to $L$. infantum in this country.
\end{abstract}

Case presentation: A 7I-year-old Spanish woman who has been living in Mendoza, Argentina, during the last 40 years presented with a history of high fever and shivering, anemia, leukopenia and splenomegaly over two years. Argentinian doctors did not suspect visceral leishmaniasis even when the histological analysis revealed the presence of "intracytoplasmatic spheroid particles compatible with fungal or parasitic infection". After a serious deterioration in her health, she was taken to Spain where she was evaluated and visceral leishmaniasis was established. Specific identification of the parasite was done by PCR-ELISA, isoenzyme electrophoresis and RAPD-PCR.

Conclusion: We would like to point out that: i) cases such as the one described here, which appear in non-endemic areas, can pass unnoticed by the clinical physician. ii) in countries in which these introduced cases reside, in-depth parasitological studies are required into vectors and possible reservoirs to rule out the rare case of local infection and, once infection has taken place, to ensure that this does not spread by anthroponotic transmission or a competent reservoir.

\section{Background}

Leishmaniasis is a parasitic infection caused by the obligate intracellular protozoa Leishmania and is transmitted by the bite of the sand fly. Leishmania currently infects about 12 million people in 88 countries, with an approximated incidence of 0.5 million cases of visceral 
leishmaniasis and 1.5 million cases of cutaneous leishmaniasis $\quad$ http://www.who.int/tdr/diseases/leish/disea seinfo.htm. The different clinical forms of leishmaniasis are the result of infection by different species of the parasite. Visceral leishmaniasis, fatal if left untreated, is typically caused by $L$. donovani, $L$. infantum and $L$. chagasi (synonimous to $L$. infantum). Visceral leishmaniasis due to $L$. infantum is a zoonosis in which dogs are the main reservoirs. In adition to the conventional zoonotic cycle, L. infantum infection could, in some cases, spread following an anthroponotic cycle. L. infantum is also responsible for cutaneous and mucosal leishmaniasis [1-3].

The question "Where have you been?" is a common one asked by doctors in Northern Europe and America when faced with clinical symptoms not typical of their country. There are numerous cases of visceral leishmaniasis and cutaneous leishmaniasis diagnosed in patients who have been travelling in the Mediterranean basin or Central or South America [4-8]. A similar situation occurs with veterinary surgeons and canine leishmaniasis. This question must also arise in the clinics of developing countries in which non-autochthonous cases such as the one described here can appear.

\section{Case presentation}

A 71-year old Spanish woman who has been living in Mendoza, Argentina, during the last 40 years. She has always been in good health and does not take regular medication. In June, 1998, she began to present high fever and shivering mainly in the evening and poor general health. She was submitted to in-depth clinical studies in Mendoza, Argentina, without reaching any definitive diagnosis. Laboratory examination revealed: haemoglobin: 9.4 g/dL, WBC: $1600 / \mathrm{mL}$ with $13 \%$ lymphocytes and $4 \%$ mononuclear cells, and polyclonal immunoglobulinopathy. She had splenomegaly. She was treated with antipyretic agents (Metamizol) and empirical antibiotics (cephalosporines) and in October 1999 was submitted to splenectomy but continued with the same symptomatology. Histopathological study of the spleen revealed "Giemsa-stained histocytic intracytoplasmatic spheroid particles compatible with fungal or parasitic infection". In spite of this diagnosis, Leishmania was not suspected and, therefore, no specific treatment was prescribed.

After a serious deterioration in her health and on request of her nephew physician, she was taken to Spain where she was admitted in May 2000 to the Hospital Virgen de las Nieves de Granada, where, on the basis of previous findings, visceral leishmaniasis was suspected. Bone marrow puncture was carried out and blood was extracted to obtain serum. The specific antibody titre against Leishmania, detected by indirect immunofluorescence was $1 / 1280$ [9]. Microscopic observation of Giemsa-stained smears
[10] revealed the presence of amastigotes in bone marrow and the promastigote form was observed in Minimum Essential Medium Eagle (Gibco) supplemented with 20\% fetal calf serum [10]. Kinetoplast DNA of $L$. infantum was detected in the bone marrow aspirate using PCR-ELISA [11]. Treatment with Glucantime $e^{\mathrm{R}}(20 \mathrm{mg} / \mathrm{Kg}$ daily for 4 weeks) [12] was followed by complete remission of symptoms and the patient returned to Mendoza, Argentina, in excellent health.

\section{Specific identification of the parasite}

PCR-ELISA [11] revealed that the species present was $L$. infantum, and after mass culture of the parasites, isoenzyme electrophoresis [13] in starch gel identified the strain (MHOM/?/2000/DP517) as belonging to the zymodeme MON-27 of $L$. infantum. This zymodeme differs from $L$. infantum MON-1 in the NP1 enzyme that presents a relative electrophoretic mobility of 130 [14]. Also, the RAPD-PCR technique was applied [15] and revealed a closer association between the problem strain and a strain of $L$. chagasi used as a control (Figure 1).

\section{Discussion}

In Argentina, there have been a total of 16 recorded cases of leishmaniasis with visceral symptomatology since 1923. Of these, 2 were considered to have been imported from Italy [16] and Yugoslavia [17], one was of unknown origin [18], and the remaining 13 were autochthonous to the provinces of Salta, Jujuy, Santiago del Estero and Chaco (northern Argentina) [19-26]. In these provinces, tegumentary leishmaniasis (cutaneous, cutaneomucosal and mucosal leishmaniasis) owing to L (Viannia) braziliensis is endemic [26]. Recently, cases of tegumentary leishmaniasis caused by L. (Leishmania) amazonensis [27] have been described. There has also been a case of visceral leishmaniasis due to L. (Leishmania) mexicana in a patient with AIDS [28]. Owing to i) the absence of the L. chagasi vector where the cases appeared in Argentina, ii) geographical overlap with the region of endemic cutaneous leishmaniasis, iii) simultaneous symptomatology of tegumentary leishmaniasis and iv) a lack of parasite classification in recorded cases of visceral leishmaniasis, it has been postulated that these could be due to a visceralization of cutaneous leishmaniasis [26].

L. (Leishmania) chagasi is the etiological agent of visceral leishmaniasis in the New World and is considered to be synonymous to $L$. infantum, the only causal agent of visceral and tegumentary leishmaniasis in western European Mediterranean countries. Important outbreaks of L. chagasi have been recorded in the last decade and an increase in its distribution in several Latin American countries such as Brazil and Paraguay but its presence has not yet been recorded in Argentina [26]. The city of Mendoza, (32 ${ }^{\circ} 53^{\prime}$ LS, $68^{\circ} 49^{\prime} \mathrm{LW}$ ) is more than $800 \mathrm{~km}$ away from the area 


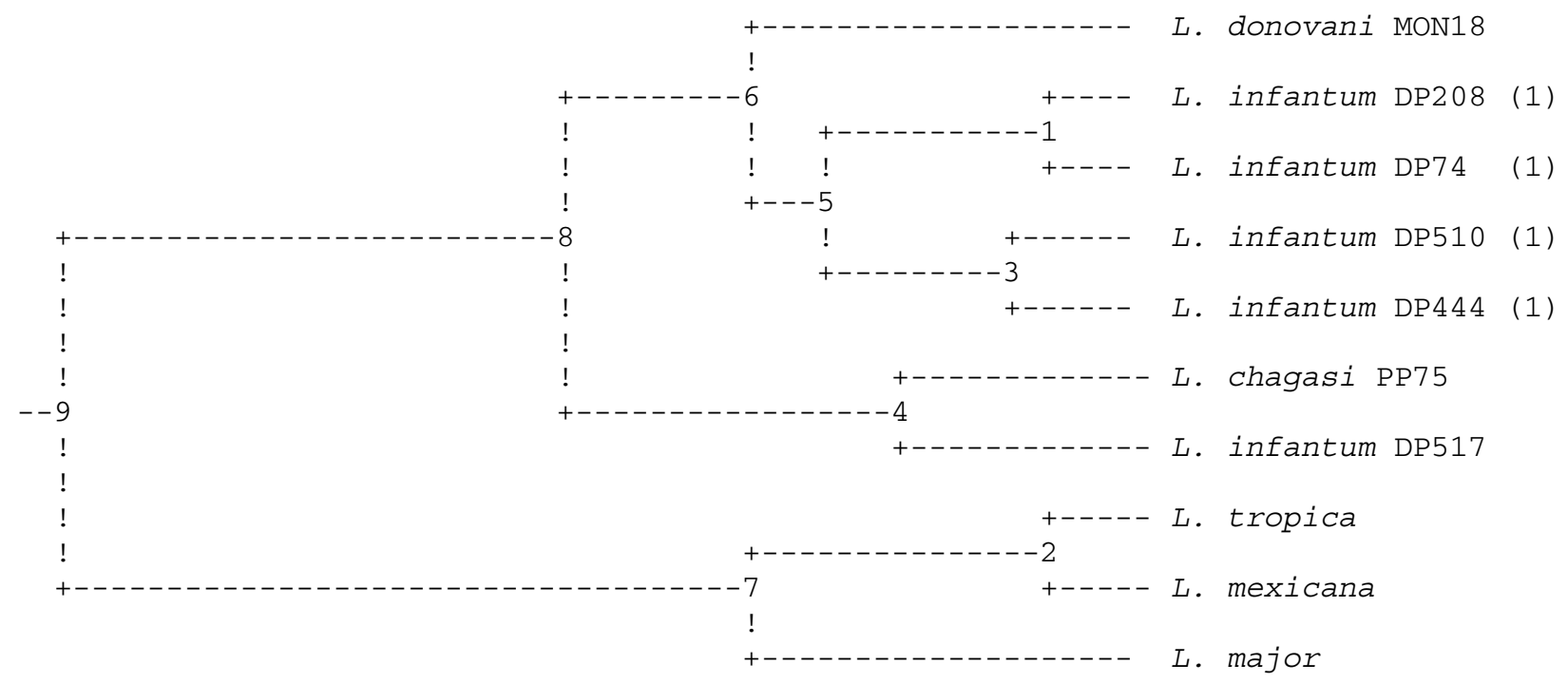

\section{Figure I}

Dendrogram Based Nei's Genetic distance: Method = UPGMA Modified from NEIGHBOR procedure of PHYLIP Version 3.5. (I) are strains isolated from southern Spain: DP74 and DP208 are eastern strains and DP440 and DP5I0 are central-western strains. DP5I7 is the strain from this case report. L. donovani MONI8 is from Portuguese origin.

of transmission of tegumentary leishmaniasis or from the last recorded case of leishmaniasis with visceral symptomatology in Argentina in 1989, in a completely different ecological region to those where sand fly insect vectors are found. This could explain why Argentinian doctors did not suspect this disease even when the histological analysis revealed the presence of intracellular parasites. On the other hand, sporadic cases of tegumentary leishmaniasis in migrants, an exotic disease in Mendoza but not in Argentina, were adequately recorded, diagnosed and treated by the local health service in Mendoza.

The patient travelled regularly to Spain, although when she became ill she had not been to this country in the previous two years. In 1985, she went on holiday to Brazil and six months before her first symptoms had visited Santiago de Cuba (Cuba) and Cancun (Mexico). Every year she goes to Santiago de Estero (Argentina) for 15-20 days, a place she had just visited before becoming ill and in which tegumentary leishmaniasis due to L. (Viannia) braziliensis is endemic $[26,29]$.

In Mexico there are few cases of visceral leishmaniasis and these seem to be confined to the states of Chiapas, Guerrero, Puebla and Tabasco $[1,30]$. No case has been described in the Yucatan Peninsula, the region in which Cancun, the place visited by the patient, is located. Leish- maniasis is not endemic in Cuba $[1,31]$ and these two countries can, therefore, be ruled out as the source of the infection. It is also unlikely that the infection took place in Brazil since the patient had not visited this country in the last 15 years. However, she always visited Spain during Summer and stayed for several months in regions known to be endemic for leishmaniasis in the provinces of Granada, Barcelona and Valencia. It is, therefore, likely that the patient was infected in Spain because of: i) more opportunities for infection due to the patient's frequent and prolonged visits. ii) the enzymatic polymorphism of the isolate. This belongs to a different zymodeme than MON-1, the only one identified to date in America, while there is a clear presence of the L. infantum polymorphism in Spain $[13,15]$.

Dendrograms constructed using the RAPD technique agree with those developed from isoenzymatic data for the separation of species but coincide little for within-species data, reflecting the heterogeneity of the strains belonging to the same zymodeme. Nevertheless, these RAPD dendrograms reflect a geographical structuration of the isolates. Figure 1 shows how the isolate DP517 is separated from the strains of L. infantum isolated from southern Spain, possibly indicating that the infection did not happen in this Spanish region. In any case, if the patient had contracted the present infection in Spain this would 
correspond to a case of asymptomatic leishmaniasis for at least the first two years. This would not be very unusual since it is well known that infection by L. infantum can exist in a subclinical form in healthy individuals without a previous background of cutaneous or visceral leishmaniasis. In fact, in endemic regions there is a remarkably high proportion of asymptomatic carriers of Leishmania $[32,33]$. These asymptomatic individuals could, therefore, act as reservoirs for the parasite.

On the other hand, the RAPD results show a greater association between this strain and the L. chagasi control that would favour the infection occurring in Argentina. Moreover, to date the MON-27 zymodeme has only been found in Italy, a country that the patient has never visited, but could have been introduced into the country by Italian immigrants.

However, Lutzomyia longipalpis, the vector of L. chagasi, is very little represented in Argentina, and has only been captured more than $1500 \mathrm{~km}$ from Mendoza, in the Misiones province. Neither have other species with vectorial capacity for L. infantum-chagasi in Argentinian territory been found, and the only sand fly found south of $29^{\circ}$ is limited to a very small area with unique ecological characteristics $1000 \mathrm{~km}$ from the patient's place of residence. No sand flies have been recorded in the captures of insect vectors made to date in Mendoza nor are there any cases of autochthonous human or veterinary tegumentary or visceral leishmaniasis in this Argentinean province. Therefore, vectorial transmission of visceral leishmaniasis due to L. infantum-chagasi in Mendoza seems unlikely. On the other hand, the patient visited annually the province of Santiago de Estero, endemic for tegumentary leishmaniasis, with three cases of visceral leishmaniasis in the last few years, one concomitant with a mucocutaneous leishmaniasis; although Lutzomyia longipalpis was not found either in this province nor was there any record of visceral leishmaniasis in immunocompetent adults or in dogs.

\section{Conclusions}

We would like to point out that: i) cases such as the one described here, which appear in non-endemic areas, can pass unnoticed by the clinical physician. ii) in countries in which these introduced cases reside, in-depth parasitological studies are required into vectors and possible reservoirs to rule out the rare case of local infection and, once infection has taken place, to ensure that this does not spread by anthroponotic transmission or a competent reservoir.

\section{Competing interests}

None declared.

\section{Authors' contributions}

JMNM and JPL carried out the clinical study of the patient in Spain. JMS and FMM carried out the culture and specific identification of the parasite and drafted the manuscript. ODS undertook epidemiological data of leishmaniasis in Argentina. All authors read and approved the final manuscript.

\section{Acknowledgement}

Written consent was obtained from the patient for publication of this case report.

\section{References}

I. Desjeux P: Information on the epidemiology and control of the leishmaniases by country or territory. WHO/LEISH/91.30 1991:1-47.

2. Morillas-Márquez F, Martín-Sánchez J, Acedo-Sánchez C, Pineda JA, Macías J, Sanjuan-García J: Leishmania infantum (Protozoa, Kinetoplastida): Transmission from infected patients to experimental animal under conditions that simulate needlesharing. Exp Parasitol 2000, I 00:71-74.

3. Pineda JA, Macías J, Morillas F, Fernández-Ochoa J, Cara J, de la Rosa R, Mira JA, Martín-Sánchez J, González M, Delgado J, Acedo C, Lissen $E$ : Evidence of increased risk for Leishmania infantum infection among HIV-seronegative intravenous drug users from southern Spain. Eur J Clin Microbiol Infect Dis 200I, 20:354-357.

4. Katz KC, Walmsley SL, McLeod AG, Keystone JS, Detsky AS: Where are you from? $N$ Engl I Med 2002, 346:764-767.

5. Montelius S, Maasho K, Pratlong F, Lebbad M, Gregory L, Akuffo H: Skin rash for I 5 years. Lancet I998, 352:I438.

6. Scope A, Trau H, Anders G, Barzilai A, Confino Y, Schwartz E: Experience with new World cutaneous leishmaniasis in travelers. J Am Acad Dermatol 2003, 49:672-678.

7. Sotiropoulos G, Wilbur B: Two cases of cutaneous Leishmaniasis presenting to the emergency department as chronic ulcers. J Emerg Med 200I, 20:353-356.

8. Zlotogorski A, Gilead L, Jonas F, Horev L, Klaus SN: South American cutaneous leishmaniasis: report of ten cases in Israeli travelers. J Eur Acad Dermatol Venereol 1998, I I:32-36.

9. Acedo Sánchez C, Martín Sánchez J, Vélez Bernal ID, Sanchís Marín MC, Louassini M, Maldonado JA, Morillas Márquez F: Leishmaniasis Eco-epidemiology in the Alpujarra Region (Granada province, southern Spain). Int J Parasitol 1996, 25:303-310.

10. Evans D, Godfrey D, Lanham S, Lanotte G, Modabber F, Schnur L: Handbook on isolation, characterization and cryopreservation of Leishmania. UNDP/World Bank/WHO, Special Programme for Research and Training in Tropical Diseases : 1-45.

II. Martín-Sánchez J, López-López MC, Acedo-Sánchez C, CastroFajardo JJ, Pineda JA, Morillas-Márquez F: Diagnosis of infections with Leishmania infantum using PCR-ELISA. Parasitology 200I, 1 22:607-615.

12. Croft SL, Coombs GH: Leishmaniasis- current chemotherapy and recent advances in the search for novel drugs. Trends Parasitol 2003, I 9:502-508.

13. Martín-Sánchez J, Gramiccia M, Di Muccio T, Ludovisi A, MorillasMárquez : Isoenzymatic polymorphism of Leishmania infantum in southern Spain. Trans R Soc Trop Med Hyg 2003, 98:228-232.

14. Gramiccia M, Gradoni L, Pozio E: Leishmania infantum sensu lato as an agent of cutaneous leishmaniasis in Abruzzi region (Italy). Trans R Soc Trop Med Hyg 1987, 81:235-237.

15. Toledo A, Martín-Sánchez J, Pesson B, Sanchiz-Marin MC, MorillasMárquez F: Genetic variability within the species Leishmania infantum by RAPD. Mol Biochem Parasitol 2002, I I 9:257-64.

16. Acuña M, Cassaubon A, Bettinotti SI: Estudio anatomo-clínico de un caso de Kala Azar infantil (primera observación en nuestro país). La Prensa Médica Argentina 1924, I I:585-593.

17. Inda FF, Vivoli D, Vacarezza AJ: Estudio anatomo-clínico de un caso de kala-azar en el adulto (fiebre negra). Primera observación en nuestro país. La semana Médica :4 I3-424. 8/2/1934

18. Garaguso P, Benítez AJ, Fainboim A: Leishmaniosis visceral. Actualización a propósito de un caso autóctono. Rev Hosp Niños Bs As 1989, 3 1:200-204. 
19. Borzone RA: Leishmaniosis tegumentaria americana vegetante con localizaciones viscerales. Bol Inst Clin quirurg Bs As 1926, 13:322-326.

20. Benitez LEL: Leishmaniosis visceral. Rev Asoc Med Arg 1967, 8:610-612.

21. Fernández Ithurrat E: Un caso de leishmaniosis visceral autóctona. El Día Médico:|14. 6/1/194|

22. Fonso Gandolfo $C$, Ink J: sobre un caso de leishmaniosis visceral. Estudio clínico experimental. Rev med y Cienc Af 1947, 9395:36-43.

23. Mazza S: Leishmaniosis tegumentaria y visceral. Bol Inst Clin Quirurg Bs As 1926, 13:208-216.

24. Mazza S, Cornejo Arias J: Primeros casos autóctonos de kalaazar infantil comprobados en el norte de la República. Bol lnst Clin Quirurg Bs As 1926, 13:140-144.

25. Wilde H, Di Carlo FC, Pessat OAN: Kala-Azar (Leishmaniosis visceral) autóctono. Su tratamiento con derivados antimoniales. El Día Médico 1956, 84:2629-2636.

26. Salomón OD, Sosa Estani S, Rossi GC, Spinelli GR: Presencia de Lutzomyia longipalpis y situación de la leishmaniasis visceral en Argentina. Medicina (Buenos Aires) 2001, 61:174-178.

27. Frank FM, Fernández MM, Taranto NJ, Cajal SP, Margni RA, Castro E, Thomaz-Soccol V, Malchiodi EL: Characterization of human infection by Leishmania spp in the Nordhwest of Argentina: immune response, double infection with Trypanosoma cruzy and species of Leishmania involved. Parasitology 2003, 1 26:31-39.

28. Nocito I, Serra E, Montero A: Visceral involvement due to Leishmania mexicana in a patient with acquired immunodeficiency syndrome. Am J Med 2002, I I 3:260-262.

29. Cuba CA, Torno CO, Ledesma O, Visciarelli E, Garcia S, Prat MI, Costamagna R, Barbieri L, Evans DA: Human cutaneous leishmaniasis caused by Leishmania (Viannia) braziliensis in Santiago del Estero, Argentina: identification of parasites by monoclonal antibodies and isoenzymes. Rev Inst Med Trop Sao Paulo 1996, 38:4|3-42I.

30. Monroy-Ostria A, Sanchez-Tejeda G: Molecular probes and the polymerase chain reaction for detection and typing of Leishmania species in Mexico. Trans R Soc Trop Med Hyg 2002, 96: I0 I-4.

31. Zeledon R: Leishmaniasis in the Caribbean Islands. A review. Ann N Y Acad Sci 1992, 653:154-60.

32. Le Fichoux I, Quaranta JF, Aufeuvre JP, Lelievre A, Marty P, Suffia I, Rousseau D, Kubar J: Occurrence of Leishmania infantum parasitemia in asymptomatic bloor donors living in an area of endemicity in southern France. J Clin Microbiol 1999, 37:1953-1957.

33. Pineda JA, Martín-Sánchez J, Macías J, Morillas F: Leishmania spp infection in injecting drug users. Lancet 2003, 360:950-95I.

\section{Pre-publication history}

The pre-publication history for this paper can be accessed here:

http://www.biomedcentral.com/1471-2334/4/20/prepub

\section{Publish with Bio Med Central and every scientist can read your work free of charge}

"BioMed Central will be the most significant development for disseminating the results of biomedical research in our lifetime. "

Sir Paul Nurse, Cancer Research UK

Your research papers will be:

- available free of charge to the entire biomedical community

- peer reviewed and published immediately upon acceptance

- cited in PubMed and archived on PubMed Central

- yours - you keep the copyright
BioMedcentral 